\title{
Design and Development of Downdraft Gasifier to Generate Producer Gas
}

\author{
Darbi Roslee ${ }^{1}$, Sulastri Sabudin ${ }^{1}$, Nadhirah Aqilah Noor Ariffin ${ }^{2 *}$, Fathin \\ Nadhirah Jamari ${ }^{2}$ and Mohd Faizal Mohideen Batcha ${ }^{1}$
}

\author{
${ }^{1}$ Center for Energy \& Industrial Environment Studies, Universiti Tun Hussein Onn Malaysia,86400 Parit Raja, Batu \\ Pahat, Johor, MALAYSIA. \\ ${ }^{2}$ Department of Mathematical Science, Faculty of Science, Universiti Teknologi Malaysia, 81310 Skudai, Johor, \\ MALAYSIA.
}

Received 1 August 2018; Accepted 20 August 2018; Available online 30 October 2018

\begin{abstract}
The drive towards renewable energy become intense nowadays due to the increasing price of fossil fuels and depletion of their sources. Among promising resource of renewable energy is the biomass. In Malaysia, oil palm biomass are available in large quantity and suitable for conversion into value added bio-fuels. In this study, an-innovative small-scale downdraft gasifier was designed, development and tested for biomass gasification. The gasifier operates at flowrate less than $0.1 \mathrm{~m}^{3} / \mathrm{s}$ with a capacity of $5 \mathrm{KW}$. During testing and commissioning of the gasifier, the maximum efficiency of the gasifier was found to be about $71 \%$ when firing empty fruit bunch pellets. This gasifier has potentials to be up scaled for actual use either for domestic or industrial use.
\end{abstract}

Keywords: Design, biomass gasifier, producer gas, efficiency

\section{Introduction}

Reducing energy consumption is always beneficial no mankind, as the present available energy resources were prolonged while reducing the environmental impact to our world. Society today should always opt for energy efficiency while looking into the utilization of renewable energy such as solar, wind, biomass and hydro [1]. Most of the developing countries has growing their interest in biofuel development and providing greater access to clean liquid fuels while helping to address the issues such as increase in global warming and fuel price concerns associated with petroleum fuels [5]. In countries with tropical climate such as Malaysia, biomass is one of the popular energy resource. In Malaysia particularly, biomass from oil palm milling is available in abundant quantities.

One of the established methods in deriving energy from biomass is the thermochemical conversion, especially gasification. Gasification is basically obtained by limiting the amount of air during chemical reaction at sub-stoichiometric level. As such, the reaction becomes an incomplete combustion and produces producer gas (synthetic gas). This process has four phase namely drying, pyrolysis, oxidation, and reduction. The drying process occurs at around $100^{\circ} \mathrm{C}$ and removes moisture from the fuel. The pyrolysis process occurs at around $200-300^{\circ} \mathrm{C}$, where volatiles were released and char was produced. Oxidation process is basically combustion, where the fuel reacts with oxygen to produce carbon dioxide and more importantly heat, for the subsequent gasification reactions. Finally, in gasification, the char reacts with air to produce methane, carbon monoxide and hydrogen which cumulatively known as producer gas that are combustible. The stages in a typical gasifier are presented by [6] as in Fig. 1. 


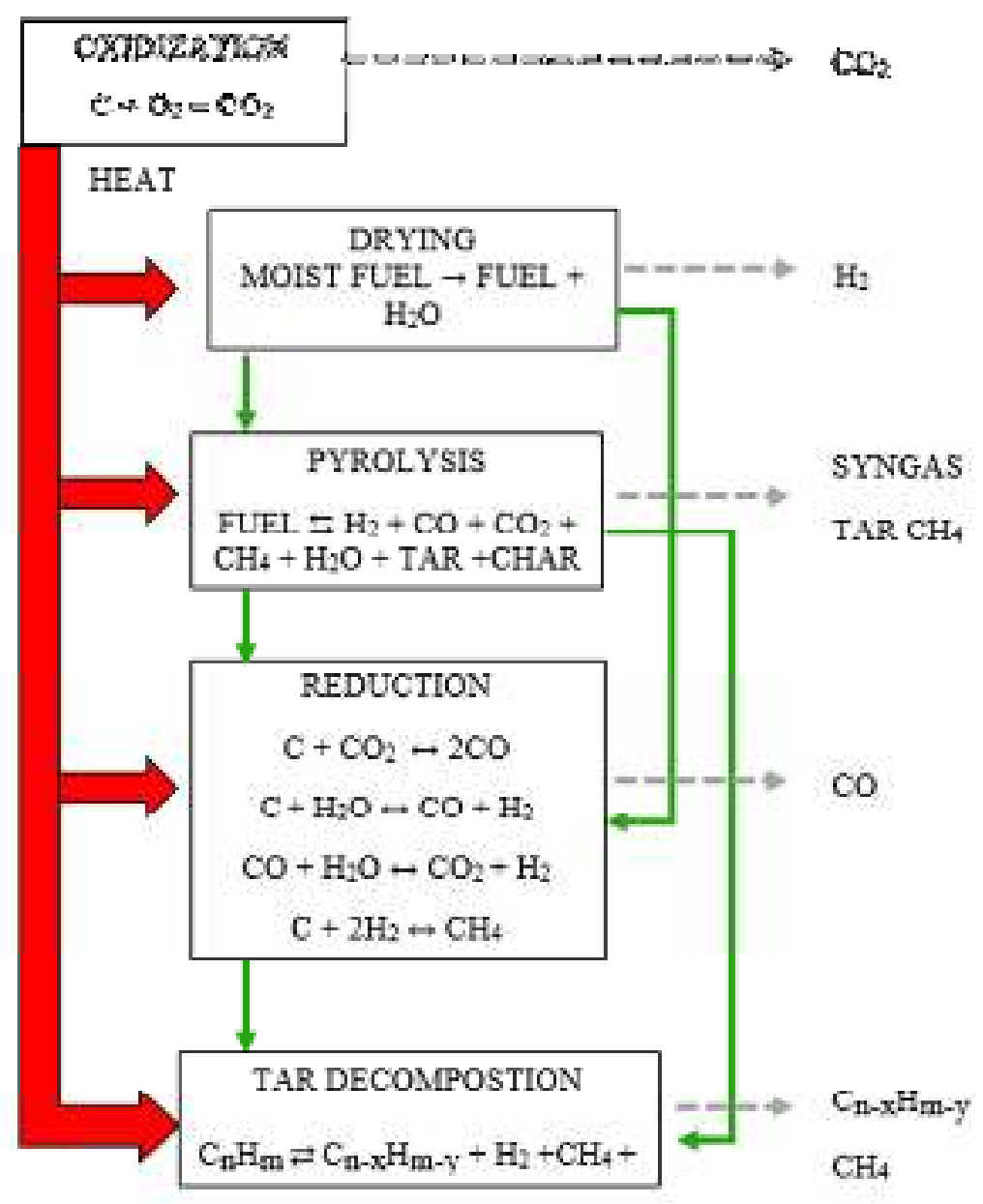

Fig. 1: Stages of gasification process [6]

The focus of this study is to design and analyze a small-scale downdraft gasifier with a capacity of $5 \mathrm{~kW}$. This gasifier is to produce syngas for domestic application such as domestic cooking. The fuel oil palm biomass namely the oil palm shell.

\subsection{Gasifier Types}

Types of gasifier design depends of the fuel availability, moisture content, ash content and end user application. Gasifiers design is a simple construction, it is made from the steel or concrete and operate at low gas velocity, high carbon conversion with the long residence time of solid [8]. Biomass gasifier is more difficult to gasify compared to fossil fuel cause of presence of complex ligno-cellulosic structures [4]. The biomass gasifier types are shown in Fig. 1.

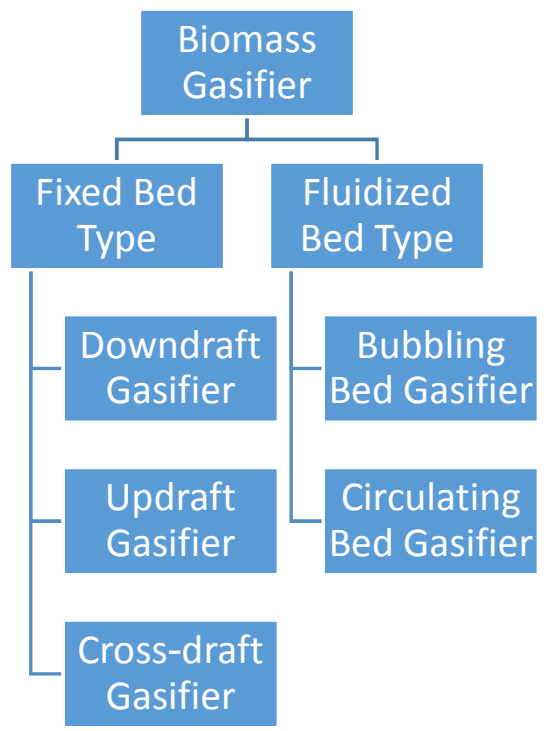

Fig. 2: Types of biomass gasifier [8] 
Moving bed type or fixed bed type gasifier gasifies biomass using a cylindrical reactor. It is having a bed of solid fuel particles through interaction of the air, oxygen, steam and gas in gasifying. The gas produce will pass either up or down [8]. It can be classified into three types which is downdraft, updraft and cross-draft gasifier [9] as shown in Fig. 3 . Each depends on the gas flow direction on each of the gasifier types. Regions of reaction distribution positioning which is drying, pyrolysis, combustion and reduction, for fixed bed reactor it is depending on type of gasifier [10]. Differences of reactor design was basically to accommodate various type of fuel.

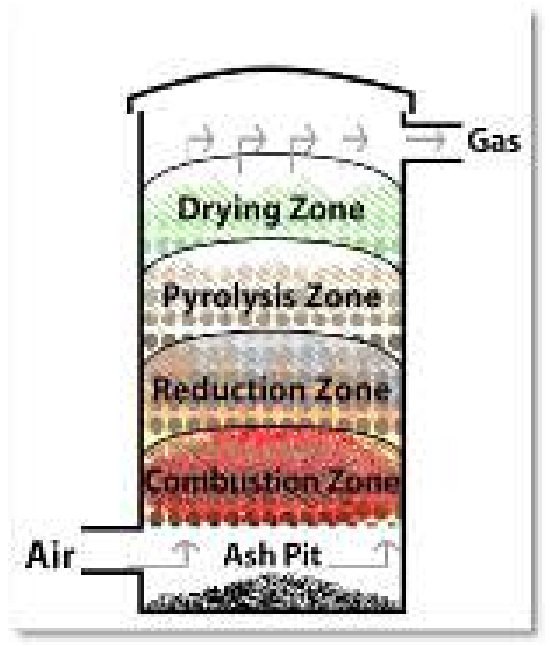

(a) Updraft

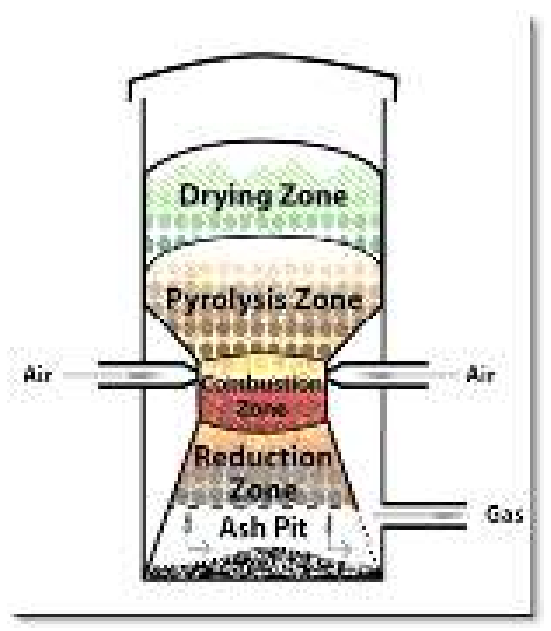

(b) Downdraft

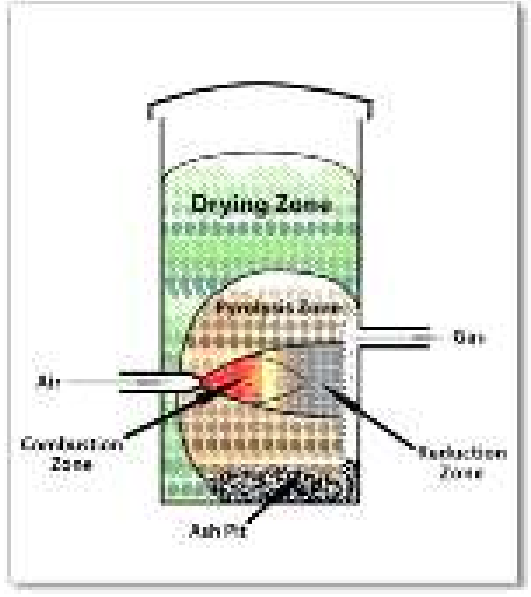

(c) Cross-draft

Fig. 3: Types of gasifier (a) Updraft (b) Downdraft and (c) Cross-draft

\subsection{Biomass Gasification}

Biomass gasification process of converting the biomass with a mixture of combustion and noncombustion gas to produce a gas. In other word biomass gasification mean incomplete combustion [16]. The thermal-conversion of the gasification is below $40 \%$ combustion. Gasifier is use for energy production that widely used in biomass. Biomass gasification consists conversion of the solid or liquid organic compound in a gas or vapor phase [17]. The gas phase that produce are usually called syngas that has high temperature and can be used to generate a power and production of biofuels [13]. At the solid phase, char produce from the organic unconverted fraction and the inert material that threated by biomass gasification process [6]. Quality of the syngas depends of the temperature value and tar content produces by gasification process. Good quality of the syngas has high temperature value and low of tar content [15]. The gas mixture to produce syngas is carbon monoxide (CO), hydrogen $\left(\mathrm{H}_{2}\right)$, methane $\left(\mathrm{CH}_{4}\right)$ and carbon dioxide $\left(\mathrm{CO}_{2}\right)$. Other gases can also be present in the syngas such as inert gases nitrogen $\left(\mathrm{N}_{2}\right)$. It is happen depends on the biomass treated and while the operational conditions of the gasification system [6]. The char from the gasifier at the solid phase. Char is a mixture of the ash, largely carbon and unconverted organic fraction. Gasification technology and the operational conditions will affect the amount of the unconverted organic fraction [7]. 


\section{Materials and Methods}

\subsection{Product Design Structure}

The design has 16 parts and divided by 2 subassembly: the gasifier body and body filter guts. The design consists a filter box to filter the fly ash with a circulating water tank and filter chamber. The schematic design with the function of the part shown in Fig. 4. The filter body was designed for good cleaning for the tar content, ash content, water absorption in the producer gas, to ensure clean and high quality gas obtained. Gas cooling is necessary in the present work to reduce thermal stress on the gasifier and piping system.. The material used as filter were fine wiremesh integrated with dried corncobs which has good permeability to assist producer gas flow and reduce pressure drop which may result blowback during operation. The reactor, grate and other parts were made from stainless and mild steel to ensure strength and ability of the system to ensure structural integrity. The assembly drawing of the downdraft gasifier is shown in Fig. 4.

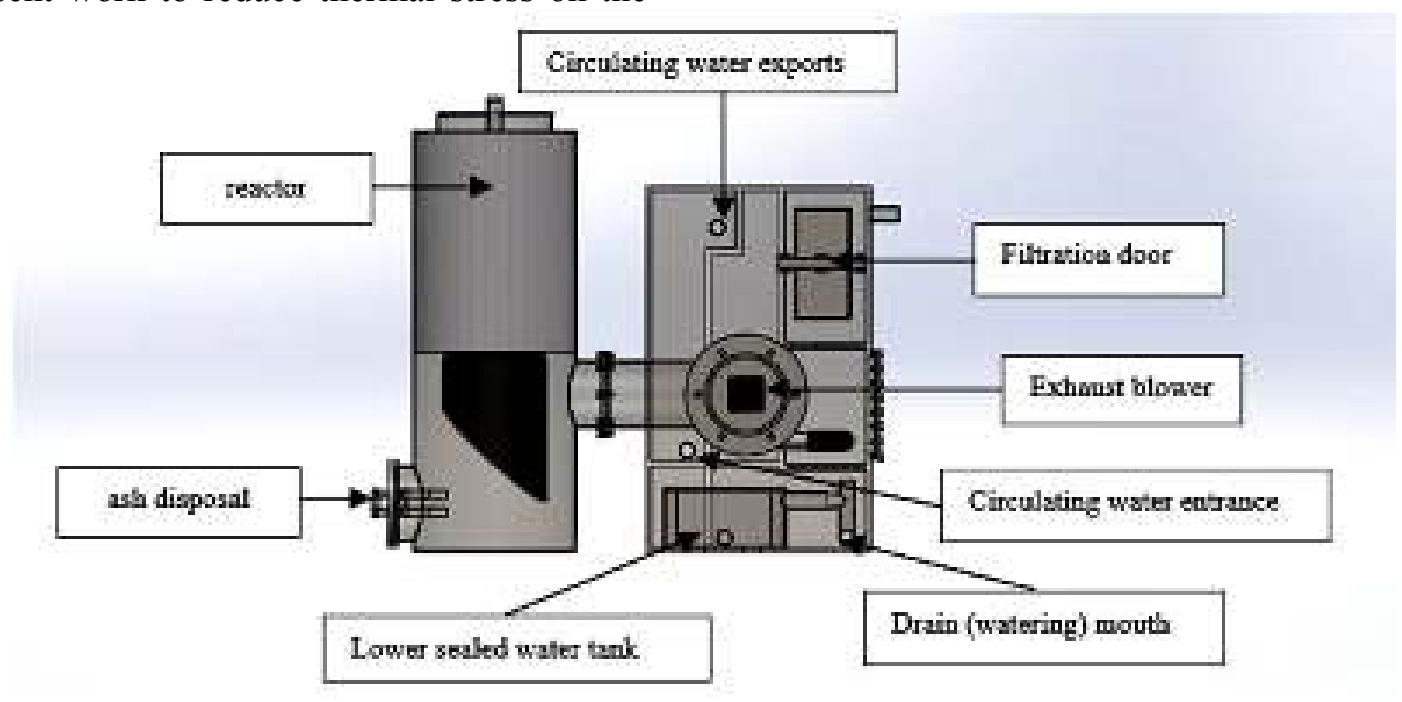

Fig. 4: Final Design of the downdraft gasifier (front view)

\subsection{Thermal analysis}

Thermal analysis is one of the important analysis in the present study. This is because the gasifier is subjected to thermal load significantly in comparison with other form of loads such as structural loads. The thermals stresses arise from the high temperature ambient inside the gasifier which can be divided into four distinct regions, namely the drying region, pyrolysis region, oxidation (or combustion) and finally the reduction zone. Each zone has different temperature range and this will affect the structural integrity during gasification process. The analysis was limited to gasifier body alone hence this is the region the high temperature ambient occurs. All thermal analysis was done via simulation in the SolidWorks 2017, and later observed during experimental works.

\section{Results and Discussion}

\subsection{Thermal analysis}

Thermal analysis was carried out with the aid of SolidWorks 2017. Figure 5 to 8 shows the temperature distribution in the downdraft gasifier during gasification process. The temperature varied from high temperature at the bottom at about $1000^{\circ} \mathrm{C}$ and reduced towards the upper region to $400^{\circ} \mathrm{C}$. This is due to the chemical reaction taking place intensely at the bottom of the gasifier unit. The temperature manifests the amount of heat released during oxidation and then transferred to the walls and overall, the temperature distribution was found to be much lower than the maximum allowable temperature of the gasifier which is about $1400^{\circ} \mathrm{C}$ taken from its allowable temperature. This was also based on the material of the gasifier which was made fromthe stainless steel. 


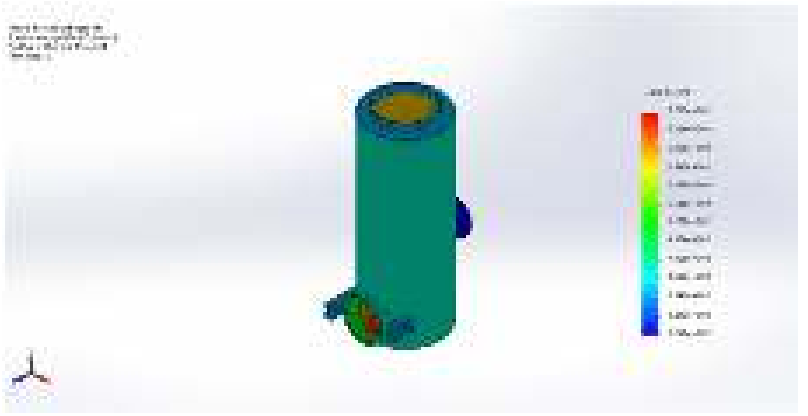

Fig. 5: Overall Temperature Distribution

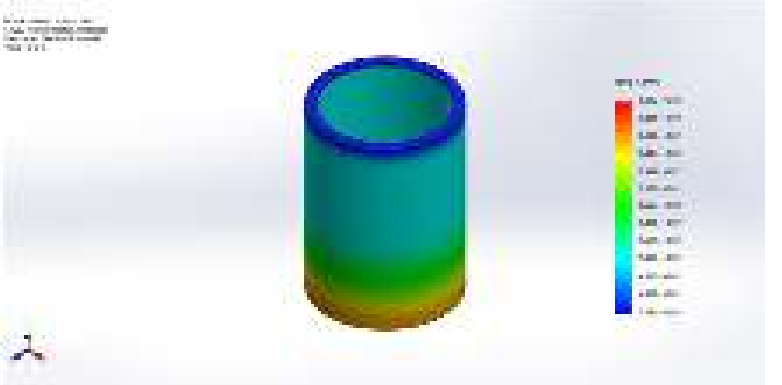

Fig. 7: Temperature Distribution at the throat

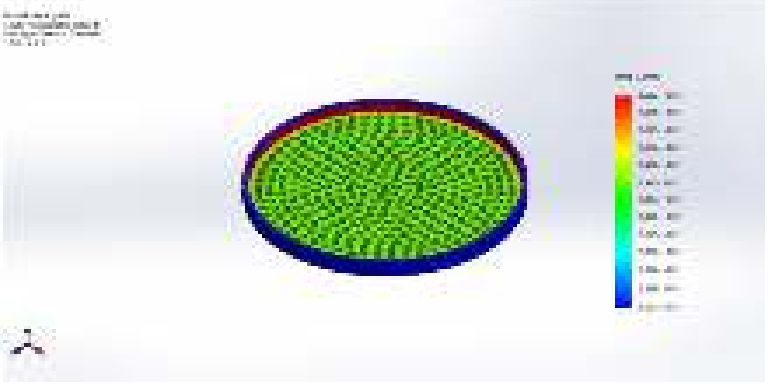

Fig. 8: Temperature Distribution at the Grate

\subsection{Synthetic gas composition}

For syngas analysis result, a chromatograph gas model GC-2014 Shidmazu was used. The composition were predicted on the volume basis of the synthetic gas that produce. For testing the gasifier using the EFB pellet fuel, the air velocity of the experiment was $1.60 \mathrm{~m}^{3} / \mathrm{s}$. The element of the synthetic gas produce composition for air velocity of $1.60 \mathrm{~m}^{3} / \mathrm{s}$ can be seen at the Table 1 below:

Table 1: Main elements of synthetic gas composition

\begin{tabular}{cc}
\hline Component & Vol \% \\
\hline $\mathrm{H}_{2}$ & $9.25 \%$ \\
$\mathrm{~N}_{2}$ & $58.53 \%$ \\
$\mathrm{CH}_{4}$ & $4.59 \%$ \\
$\mathrm{CO}_{2}$ & $12.52 \%$ \\
$\mathrm{CO}$ & $8.86 \%$ \\
\hline
\end{tabular}

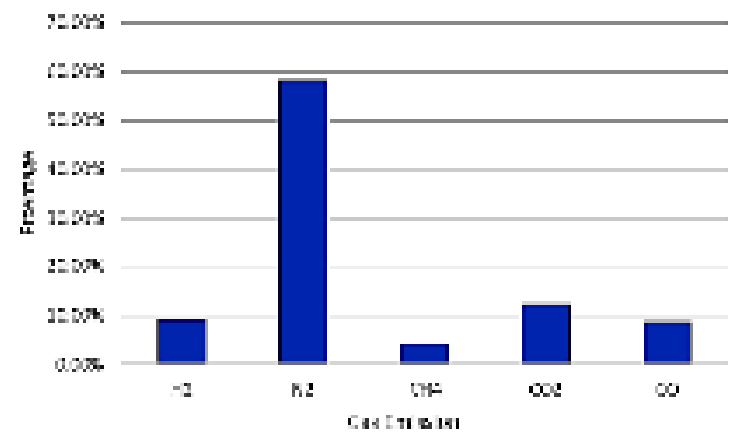

Fig. 9: Graph Synthetic Gas Composition for EFB Pellet

The graph shows the result of the synthetic gas composition for EFB pellet. This result was trying during testing the downdraft gasifier. Based on the graph result, the highest percentage in the gas emission was nitrogen $\left(N_{2}\right)$ which is $58.53 \%$ followed by carbon dioxide $\left(\mathrm{CO}_{2}\right)$ with $12.52 \%$. Then the hydrogen $\left(\mathrm{H}_{2}\right)$, carbon monoxide and methane with the $9.25 \%, 8.86 \%$ and $4.59 \%$ approximately.

Lower heating value of component of synthetic gas is mentioned in table below:

Table 2: LHV of components of producer gas

\begin{tabular}{cc} 
Component & $\mathrm{LHV}\left(\mathrm{KJ} / \mathrm{m}^{3}\right)$ \\
\hline $\mathrm{H}_{2}$ & 10788 \\
$\mathrm{~N}_{2}$ & - \\
$\mathrm{CH}_{4}$ & 35814 \\
$\mathrm{CO}_{2}$ & - \\
$\mathrm{CO}$ & 12622 \\
\hline
\end{tabular}

Thus, the lower heating value of gas $\left(L H V_{\text {gas }}\right)$ for air velocity $1.60 \mathrm{~m}^{3} / \mathrm{s}$ is calculated using formula as shown below:

LHV gas $=\sum$ (volume $\%$ of component $\times$ LHV of component)

$$
\begin{aligned}
= & (0.0925 \times 10788)+(0.5833 \times 0)+ \\
& (0.0459 \times 35814)+(0.1252 \times 0)+ \\
& (0.0886 \times 12622) \\
= & 3760.10 \mathrm{KJ} / \mathrm{m}^{3}
\end{aligned}
$$

\subsection{Efficiency of Gasifier}

The gasifier efficiency was important to be evaluated to obtain the actual amount of fuel converted to synthetic gas. There are several factors affecting the gasifier efficiency such as 
thermodynamic loss and friction. These factors are however not taken into account here, and only the cold gas efficiency (CGE) was calculated. The cold gas efficiency (CGE) is measure the gasifier performance. It is can be defined as the ratio between the flow of energy in the gas and the energy contained within the fuel. Cold gas efficiency (CGE) does not take into account that the product gas exiting the gasifier is hot. The higher the cold gas efficiency it would be better the fuel conversion. The CGE equation is given below:

$Q_{\text {gas }}=$ Volume flow rate of gas $\left(\mathrm{m}^{3} / \mathrm{s}\right)$

$H_{\text {solid }}=$ Lower heating value of solid fuel $(\mathrm{KJ} / \mathrm{kg})$

$M_{\text {solid }}=$ Solid fuel Consumption $(\mathrm{Kg} / \mathrm{s})$

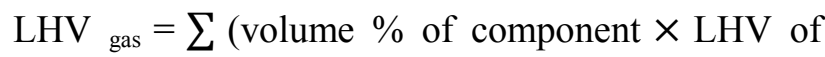
component)

$$
\begin{aligned}
& =(0.0925 \times 10788)+(0.5833 \times 0)+ \\
& (0.0459 \times 35814)+(0.1252 \times 0)+(0.0886 \\
& \times 12622) \\
& =3760.10 \mathrm{KJ} / \mathrm{m}^{3} \\
\eta_{g} & =\frac{3760.06 \times 0.00178}{18930 \times 0.00051} \times 100 \% \\
& =70 \%
\end{aligned}
$$

\subsection{Techno-Economic Analysis}

For downdraft gasifier, the amount of use agricultural wastes and wood wastes must be considered. The cost of the product must be evaluated to identify the determinant in gasification technology potential. The gasification technology must completely economically for the environmental benefit. In order to realize this techno-economic analysis, comparison was made with usage of liquefied petroleum gas (LPG) which was commercially available, assuming that this gasifier was used as a replacement for LPG gas in a small restaurant. Based on the quick survey carried out, a small restaurant consumes about 6 units of $14 \mathrm{~kg}$ LPG cylinder per month. This value was used for analysis, which were as follows:

\section{LPG gas usage per year}

$=14 \mathrm{~kg} \mathrm{~kg} /$ cylinder $\times 6$ cylinder $/$ month $\times 12$ month/year $=1099 \mathrm{~kg}$ of LPG gas per year

\subsection{Product Cost Estimation}

Table 3: Product Cost

\begin{tabular}{cc}
\hline Item & Cost $(\mathbf{R M})$ \\
\hline Plate & 250.00 \\
Stopper socket & 14.00 \\
3 phase blower & 120.00 \\
Pipe & 45.00 \\
Steel filter & 40.00 \\
ceramic insulation & 250.00 \\
Others & 200.00 \\
Total & $\mathbf{9 1 9 . 0 0}$ \\
\hline
\end{tabular}

Table 4: Estimated Period for Production

\begin{tabular}{cc}
\hline Item & Cost (RM) \\
\hline Product cost & 919.00 \\
Monthly & 50.00 \\
maintenance cost & \\
Electricity bill & 10.00 \\
Total & $\mathbf{9 7 9 . 0 0}$ \\
\hline
\end{tabular}

It is important to highlight that certain item are charged with tax hence the total cost will be different after the charged with tax. The downdraft gasifier project only spent less than RM 1000.

The payback period for downdraft gasifier to recover the cost of machine :

$$
\begin{aligned}
& =\frac{\text { Cost of product }}{\text { Price LPG gas for year }} \\
& =\frac{\text { RM1000 }}{\text { RM2 } / \mathrm{kg} \times 1088 \mathrm{~kg} / \text { year }}=0.46 \text { years } \\
& \approx 6 \text { months }
\end{aligned}
$$

\subsection{Greenhouse Gas Emission Avoidance}

With the usage of downdraft gasifier and replacement of LPG gas for cooking, a certain amount of greenhouse gas emission can be avoided. The GHG emission factor for LPG gas is $1760 \mathrm{~kg}$ per ton of LPG gas, assume the LPG gas is butane. GHG avoidance is as following:

The amount of avoidance usage of $\mathrm{CO}_{2}$

$=1760 \times 1.088=1915 \mathrm{~kg}$ of $\mathrm{CO}_{2}$ 
Therefore, about $1915 \mathrm{~kg}$ of $\mathrm{CO}_{2}$ can be avoided for usage in a small restaurant using this downdraft gasifier.

\section{Conclusions}

In this study, an innovative downdraft gasifier has been designed, developed and tested to gasify oil palm biomass to produce producer gas. The producer gas is a bio-fuel which can be used to replace the present consumption of liquefied petroleum gas (LPG) which is a fossil fuel. The objectives were successfully achieved whereby a 5 $\mathrm{kW}$ downdraft gasifier unit has been developed. The design was done using SolidWork 2017, followed by thermal analysis at critical parts. From the operation of the gasifier, it was found that the producer gas contains (carbon monoxide (CO) $8.86 \%$, hydrogen $\left(\mathrm{H}_{2}\right) 9.25 \%$, carbon dioxide $\left(\mathrm{CO}_{2}\right)$ $12.52 \%$, Methane $\left(\mathrm{CH}_{4}\right) 4.59 \%$ and Nitrogen $\left(\mathrm{N}_{2}\right)$ $58.53 \%$

The author had done the analysis toward engineering and experimental element during the testing and commissioning of the downdraft gasifier. As the result of the performance efficiency of the downdraft gasifier was $70 \%$. This downdraft gasifier can stand with the high temperature at the bottom region at about $1000^{\circ} \mathrm{C}$ to $400^{\circ} \mathrm{C}$ to the upper region. This validates the thermal simulation done by using the SolidWork 2017.

This downdraft gasifier was also being economically viable and provides environmental benefit. The return of investment was calculated to be 6 months for a small restaurant, when the LPG cylinder was replaced by using this downdraft gasifier. Also by using this downdraft gasifier, the small restaurant can reduce the LPG usage about $1088 \mathrm{~kg}$ gas per year. This reducing of gas LPG mean can avoid the greenhouse gas emission $\mathrm{CO}_{2}$ about $1915 \mathrm{~kg} \mathrm{CO}$.

Acknowledgments: This study was supported in part by grants from the Center of Energy and Industrial Environment Studies, Faculty of Mechanical and Manufacturing, Universiti Tun Hussein Onn Malaysia with Faculty of Science, Universiti Teknologi Malaysia.

\section{References}

[1] Ingle N. A. and Lakade S. S. Design and Development of Downdraft Gasifier to
Generate Producer Gas. Energy Procedia, Volume 90, (2015), pp. 423-431.

[2] Andsaler A. R., Khalid A. and Jaat N. Simulation and Modelling of Mixture Formation under Variant Ambient Condition and Injection Pressure of Biodiesel Spray. International Journal of Integrated Engineering, Volume 9, (3), (2017), pp. 18-23.

[3] Ismail M. M., Fawzi M., Zulkifli F. H. and Osman S. A. CNG-Diesel Dual Fuel Controlling Concept for Common Rail Diesel. International Journal of Integrated Engineering, Volume 10, (3), (2018), pp. 8892.

[4] Nirapure S., Singh M., and Nigam S. Downdraft Gasifier: A Review. IOSR J. Mech. Civ. Eng. Ver. IV, Volume 12, (4), (2015), pp. 2278-1684.

[5] Samiran N. A., Jaafar M. N. M., Ng J. H., Lam S. S., and Chong C. T. Progress in biomass gasification technique - With focus on Malaysian palm biomass for syngas production. Renew. Sustain. Energy Rev., Volume 62, (2016), pp. 1047-1062.

[6] Molino A., Chianese S., and Musmarra D. Biomass gasification technology: The state of the art overview. Journal of Energy Chemistry. (2016).

[7] Venselaar J. Design Rules for Down Draft Wood Gasifiers: A Short Review, (1986), pp. $1-24$

[8] Sansaniwal S. K., Pal K., Rosen M. A., and Tyagi S. K. Recent advances in the development of biomass gasification technology: A comprehensive review. Renew. Sustain. Energy Rev., Volume 72, (2017), pp. 363-384.

[9] Guangul F. M., Sulaiman S. A., and Ramli A. Gasifier selection, design and gasification of oil palm fronds with preheated and unheated gasifying air. Bioresour. Technol., Volume 126, (2012), pp. 224-232.

[10] Patra T. K. and Sheth P. N. Biomass gasification models for downdraft gasifier: A state-of-the-art review. Renew. Sustain. Energy Rev., Volume 50, (2015), pp. 583-593.

[11] Reed T. B. and Das A. Handbook of biomass downdraft gasifier engine systems. (1988).

[12] Vidian F., Basri H., and Sihotang D. Design, Construction and Experiment on Imbert Downdraft Gasifier Using South Sumatera Biomass and Low Rank Coal as Fuel. Int. J. Eng. Res. Appl., Volume 7, (3), (2017), pp. 3944.

[13] Machin E. B. et al. Tar reduction in downdraft 
biomass gasifier using a primary method. Renew. Energy, Volume 78, (2015), pp. 478483.

[14] Lettner F., Timmerer H., and Haselbacher P. Deliverable 8: Biomass gasification - State of the art description, (2007), pp. 1-91.

[15] Susastriawan A. A. P., Saptoadi H., and Purnomo. Small-scale downdraft gasifiers for biomass gasification: A review. Renew. Sustain. Energy Rev., Volume 76, (2017), pp. 989-1003.

[16] Alamsyah R., Loebis E. H., Susanto E., Junaidi L., and Siregar N. C. An Experimental Study on Synthetic Gas (Syngas) Production through Gasification of Indonesian Biomass Pellet. Energy Procedia, Volume 65, (2015), pp. 292-
299.

[17] Perkins G. and Vairakannu P. Considerations for oxidant and gasifying medium selection in underground coal gasification. Fuel Process. Technol., Volume 165, (2017), pp. 145-154.

[18] Laciak M., Kostúr K., Durdán M., Kačur J., and Flegner $\mathrm{P}$. The analysis of the underground coal gasification in experimental equipment. Energy, Volume 114, (2016), pp. 332-343.

[19] Al-Zareer M., Dincer I., and Rosen M. A. Effects of various gasification parameters and operating conditions on syngas and hydrogen production. Chem. Eng. Res. Des., Volume 115, (2016), pp. 1-18. 